\title{
Evaluation of Potential Mechanisms Controlling the Catalase Expression in Breast Cancer Cells
}

\author{
Christophe Glorieux, ${ }^{1}$ Juan Marcelo Sandoval, ${ }^{2}$ Nicolas Dejeans, ${ }^{1}$ Sandrine Nonckreman, ${ }^{3}$ \\ Khadija Bahloula, ${ }^{3}$ Hélène A. Poirel $\mathbb{D}^{3},{ }^{3}$ and Pedro Buc Calderon $\mathbb{D}^{1,2}$ \\ ${ }^{1}$ Metabolism and Nutrition Research Group, Louvain Drug Research Institute, Université catholique de Louvain, \\ 1200 Brussels, Belgium \\ ${ }^{2}$ Facultad de Ciencias de la Salud, Universidad Arturo Prat, 1100000 Iquique, Chile \\ ${ }^{3}$ Centre de Génétique Humaine, Cliniques Universitaires Saint-Luc \& de Duve Institute, Université catholique de Louvain, \\ 1200 Brussels, Belgium
}

Correspondence should be addressed to Pedro Buc Calderon; pedro.buccalderon@uclouvain.be

Received 30 August 2017; Accepted 9 November 2017; Published 28 January 2018

Academic Editor: Spencer Gibson

Copyright (C) 2018 Christophe Glorieux et al. This is an open access article distributed under the Creative Commons Attribution License, which permits unrestricted use, distribution, and reproduction in any medium, provided the original work is properly cited.

\begin{abstract}
Development of cancer cell resistance against prooxidant drugs limits its potential clinical use. MCF-7 breast cancer cells chronically exposed to ascorbate/menadione became resistant (Resox cells) by increasing mainly catalase activity. Since catalase appears as an anticancer target, the elucidation of mechanisms regulating its expression is an important issue. In MCF-7 and Resox cells, karyotype analysis showed that chromosome 11 is not altered compared to healthy mammary epithelial cells. The genomic gain of catalase locus observed in MCF-7 and Resox cells cannot explain the differential catalase expression. Since ROS cause DNA lesions, the activation of DNA damage signaling pathways may influence catalase expression. However, none of the related proteins (i.e., p53, ChK) was activated in Resox cells compared to MCF-7. The c-abl kinase may lead to catalase protein degradation via posttranslational modifications, but neither ubiquitination nor phosphorylation of catalase was detected after catalase immunoprecipitation. Catalase mRNA levels did not decrease after actinomycin D treatment in both cell lines. DNMT inhibitor (5-aza-2'-deoxycytidine) increased catalase protein level in MCF-7 and its resistance to prooxidant drugs. In line with our previous report, chromatin remodeling appears as the main regulator of catalase expression in breast cancer after chronic exposure to an oxidative stress.
\end{abstract}

\section{Introduction}

Catalase mainly catalyzes the dismutation of hydrogen peroxide $\left(\mathrm{H}_{2} \mathrm{O}_{2}\right)$ into water and molecular oxygen. This antioxidant enzyme is expressed in all major body organs especially in the liver, kidney, and erythrocytes. In these organs, catalase plays an essential role in cell defense against oxidative stress $[1,2]$. A decrease in catalase activity is thus frequently associated with several diseases. For instance, some polymorphisms into the promoter or introns of the catalase gene are involved in diabetes, hypertension, vitiligo, Alzheimer's disease, and acatalasemia $[3,4]$. Interestingly, catalase is also frequently downregulated in tumor tissues compared to normal tissues of the same origin [5-7]. In this context, when compared to their normal healthy counterparts, we have reported a severe decrease of catalase activity in TLT cells, a murine hepatocarcinoma cell line [8]; in K562 cells, a human chronic myeloid leukemia cell line [9]; and in MCF-7 cells, a human breast carcinoma cell line [10]. These observations are consistent with the study of Sun et al., who showed that immortalization and transformation of mouse liver cells with SV40 virus results in a decrease in catalase activity, which contributes to oncogenesis by increasing reactive oxygen species (ROS) level in transformed cells [11]. The mechanisms 
controlling the transcription of catalase gene are poorly understood, and diverse mechanisms have also been proposed to regulate catalase expression [3].

We explored a potential role of catalase during the acquisition of cancer cell resistance to chemotherapeutic agents. To this end, we overexpressed human catalase in MCF-7 breast cancer cells. No particular resistance against conventional chemotherapies like doxorubicin, cisplatin, and paclitaxel was observed in cells overexpressing catalase, but they were more resistant to prooxidant therapies [12]. Furthermore, we generated a resistant cell line by chronic exposure of MCF-7 cells to an $\mathrm{H}_{2} \mathrm{O}_{2}$-generating system, namely, the ascorbate/menadione (Asc/Men) combination. Catalase was overexpressed in resistant-Resox cells when compared to parental MCF-7 cells $[13,14]$. In these cells, transcription factors (i.e., RAR $\alpha$ and JunB) and other proteins belonging to coactivator or corepressor complexes (i.e., HDACs) affect chromatin remodelling and lead to the activation or repression of catalase gene [10].

Additional regulatory levels clarifying this altered catalase expression in cancer cells were also explored. Since ROS induce DNA lesions, we were interested to know whether a potential role of DNA repair pathways may have an impact on the regulation of catalase expression. Genetic alterations such as loss of heterozygosity or amplification of the catalase gene locus, although very rare, were investigated. Both posttranscriptional and posttranslational catalase modifications were also analysed regarding putative alterations of protein stability. Finally, since gene transcription is also regulated by chromatin modulation due to histone acetylation or DNA methylation, these epigenetic marks were also investigated as potential modulators of altered catalase expression in breast cancer cells.

\section{Materials and Methods}

2.1. Cell Lines and Chemicals. MCF-7 cells were purchased at ATCC (Manassas, VA, United States). An MCF-7 cell line resistant to oxidative stress (namely Resox cells) was generated by chronic exposure of cells to increasing concentrations of the prooxidant combination of ascorbate/menadione (Asc/Men) for 6 months, starting with $0.5 \mathrm{mM}$ ascorbate/ $5 \mu \mathrm{M}$ menadione to a final concentration of $1.5 \mathrm{mM}$ ascorbate $/ 15 \mu \mathrm{M}$ menadione. Cells were first treated at $50 \%$ confluence by replacing their media with fresh media containing Asc/Men. When surviving cells reached 50\% confluence, they were washed with warm PBS and treated again [13]. To avoid the development of islets of resistance, which could arise from cooperation between cells, the cells were trypsinized every 2 weeks and subcultured into new flasks. After selection, the cell line was stabilized in drug-free medium for 1 month. Cells were kept in DMEM medium supplemented with $10 \%$ foetal calf serum, in the presence of penicillin $(100 \mathrm{U} / \mathrm{ml})$ and streptomycin $(100 \mu \mathrm{g} / \mathrm{ml})$ from Gibco (Grand Island, NY, USA). Human mammary epithelial cells $250 \mathrm{MK}$ were provided by Dr. M. Stampfer and Dr. J.C. Garbe (Lawrence Berkeley National Laboratory, Berkeley, California, USA). They were maintained in a
$\mathrm{M} 87 \mathrm{~A}+\mathrm{CT}+\mathrm{X}$ medium and used between passages 8 and 10 [15].

Sodium ascorbate, menadione sodium bisulfite, MG132, actinomycin D, and 5-aza-2'-deoxycytidine were purchased from Sigma (St. Louis, MO, USA).

2.2. Conventional Cytogenetic Analysis. Metaphase chromosomes were obtained according to standard protocols from the different cell lines [16]. Briefly, cultured cells, in exponential growth phase, were treated for $4 \mathrm{~h}$ with $0.02 \mu \mathrm{g} / \mathrm{ml}$ of Colcemid (Invitrogen). Harvested cells from the flasks after trypsinization were incubated for 30 minutes at $37^{\circ} \mathrm{C}$ in hypotonic $0.055 \mathrm{M} \mathrm{KCl}$ and fixed in a 3:1 methanol : glacial acetic acid solution. Chromosome harvesting and metaphase slide preparation were performed according to standard procedures [16-18]. Twenty Reverse Trypsin Wright (RTW) banded metaphases were analysed and karyotypes were reported according to the last 2013 International System for Human Cytogenetics Nomenclature (ISCN 2013).

2.3. Fluorescence In Situ Hybridization (FISH). Specific BAC RP11-964L11 (catalase/11p13; stained with Cy3: red spots) and RP11-90K17 (control/11q14; stained with FITC: green spots) probes from the UCSC (http://genome.ucsc.edu) databases were obtained from the BACPAC Resources Centre at the Children's Hospital Oakland Research Institute (Oakland, CA, USA).

The FISH (fluorescence in situ hybridization) assay was carried out on nuclei and metaphases from fixed pellet of cell as previously described [19]. All hybridized metaphases were captured on a Zeiss Axioplan 2 microscope (Zeiss, Zaventem, Belgium) and analysed using the Isis software (Metasystems, Altlussheim, Germany).

2.4. Immunoblotting. The procedures for protein sample preparation from cell cultures, protein quantification, immunoblotting, and data analyses were performed as previously described [12, 14]. Antibody against catalase (\#AB1212) was obtained from Millipore (Merck KGaA, Darmstadt, Germany); antibodies against c-abl (\#sc-23) and p53 (\#sc126) were from Santa Cruz Biotechnology (Santa Cruz, CA, USA); antibodies against phosphocatalase Y385 (\#ab59429) and $\beta$-actin (\#ab6276) were from Abcam (Cambridge, UK); antibodies against phospho-Chk2 T68 (\#2661) and phospho-p53 S15 (\#9284) were from Cell signaling (Beverly, MA, USA); and antibody against Flag (\#F3165) was from Sigma (St. Louis, MO, USA). Protein bands were then detected by chemiluminescence, using the ECL detection kit (Pierce, Thermo Scientific, Rockford, IL, USA). When appropriate, bands obtained via Western blot analysis were quantified, using ImageJ software (http://rsb.info.nih.gov/ij/). Protein expression was normalized to that of $\beta$-actin.

2.5. Real-Time PCR. Total RNA was extracted with the TriPure reagent from Roche Applied Science Diagnostics (Mannheim, Germany). Reverse transcription was performed using SuperScript II RNase H- reverse transcriptase and random hexamer primers (Invitrogen, Grand Island, NY, USA). Sybr Green Supermix (BioRad, Hercules, CA, USA) was used for qRT-PCR. All Primers sequences were 
designed from Sigma (St. Louis, MO, USA) and provided in Table S1. The samples were incubated $5 \mathrm{~min}$ at $95^{\circ} \mathrm{C}, 40$ cycles of $10 \mathrm{~s}$ at $95^{\circ} \mathrm{C}$ and $30 \mathrm{~s}$ at $60^{\circ} \mathrm{C}$, and followed by a melting curve. The fluorescence in the samples was measured after each cycle in a Bio-Rad IQ5 thermocycler (Bio-Rad, Hercules, CA, USA). The results were calculated from the following calculation: $2^{-(\mathrm{Ct} \text { target gene - Ct EF1) }}$ and matched to the control samples.

2.6. Ubiquitination and Phosphorylation Assays. Cells were transiently transfected, at $50 \%$ confluence, with $1 \mu \mathrm{g}$ of plasmid pcDNA3 coding an ubiquitin-Flag fusion protein, a kind gift from Prof. J-B. Demoulin (UCL, Brussels, Belgium). Twenty-four hours posttransfection, cells were treated with $25 \mu \mathrm{M} \mathrm{MG} 132$ for $5 \mathrm{~h}$. Cells were washed twice with icecold PBS and then resuspended in the lysis buffer in the presence of proteases (Protease Inhibitor Cocktail, Sigma, St. Louis, MO, USA) and phosphatase inhibitors (Phosphatase Inhibitor Cocktail, Calbiochem, Merck KGaA, Darmstadt, Germany). Cell lysates were immunoprecipitated in columns containing catalase antibody (AB1212, Millipore), using coimmunoprecipitation kit from Pierce (Rockford, IL, USA). Eluates were then tested by immunoblotting.

2.7. MTT Assay. The effects of Asc/Men after incubation with DNMT inhibitor on cell metabolic status were assessed by following the reduction of MTT (3-(4,5-dimethylthiazolyl2)-2,5-diphenyltetrazolium bromide) to blue formazan [20]. Blue formazan crystals were solubilized with DMSO and the coloured solution was subsequently read at $550 \mathrm{~nm}$. Results are expressed as \% of MTT reduction compared to untreated control conditions.

2.8. Statistics. All experiments were performed at least in triplicates. Groups were analysed using unpaired $t$-test performed with GraphPad Prism software (San Diego, CA, USA). The level of significance was set at $p<0.05$.

\section{Results and Discussion}

3.1. Is a Genomic Gain of Catalase Locus in Breast Cancer Cell Lines Responsible for Catalase Overexpression in Resistant Cells? Since the human catalase gene is located on the short arm of chromosome 11 (11p13) [21] and deletion of this chromosomal region is generally associated with a decrease of catalase activity, we first focused on genetic alterations, an important hallmark of cancer. Interestingly, the deletion of chromosome $11 \mathrm{p}$ is frequently observed in later passages of SV40-transformed human fibroblasts and correlated with a low catalase activity [22]. Such alteration may occur in children affected by WAGR syndrome, a rare genetic disease in which the affected children are predisposed to develop Wilms' tumor (tumor of the kidney), aniridia (absence of the iris), gonadoblastoma, and mental retardation [23-29]. This chromosomal region was altered in the breast cancer cell lines, but karyotypes showed that chromosome 11 was not altered in MCF-7 and Resox cells compared to healthy $250 \mathrm{MK}$, a human epithelial mammary cell line (Figure 1(a)). The complete karyotype analyses of these three cell lines have been previously published [13].
Loss of alleles (i.e., loss of heterozygosity) of catalase gene was also observed in non-small-cell lung cancer and was associated with a decrease of catalase activity [30-32]. On the contrary, gain of catalase gene copy number and amplification of chromosome 11p can also explain an increased expression of catalase. This phenomenon has been observed in HL-60 cell lines rendered resistant to $\mathrm{H}_{2} \mathrm{O}_{2}$. These cells were more resistant because they have an enhanced catalase activity that correlated with an increase of gene copy number from two to eight times higher than in parental cell line [33].

We have thus investigated a potential loss of heterozygosity or a genomic gain by performing hybridization of catalase and control FISH probes on metaphases. The catalase and control FISH probes were controlled in human lymphocytes (data not shown) and normal mammary epithelial $250 \mathrm{MK}$ cells (Figure 1(b)). We observed two red (catalase locus) and two green spots (control) localized on the two chromosome 11. A genomic gain of catalase locus was observed in MCF-7 and Resox cell lines compared to $250 \mathrm{MK}$ cells: we counted 3 catalase spots, two localized on the two normal chromosome 11 and one localized on an unidentified chromosome (Figures 1(c) and 1(d)). However, the number of catalase loci remained similar in these two cell lines. For Resox cells, one subclonal population was characterized by 6 red spots and two-fold chromosome number (not shown) corresponding to $20 \%$ of total Resox population. We can conclude that this genomic gain of chromosome $11 \mathrm{p} 13$ is not involved in mechanisms leading to catalase overexpression in Resox cells.

3.2. Are Proteins of DNA Damage Pathway Involved in Catalase Expression of Breast Cancer Cells? Since the karyotypes were altered in breast cancer cell lines [13] and ROS induce DNA damage, we investigated whether the activation of DNA repair system may influence the regulation of catalase expression. To our knowledge, a putative link between this repair system and antioxidant enzyme expression as a possible response against ROS-mediated DNA damage has not yet been investigated.

Three different kinases, namely, DNA-PK (DNA-activated protein kinase), ATM (ataxia telangiectasia mutated), and ATR (ataxia telangiectasia and Rad3 related), are activated when the DNA is damaged leading to the activation of proteins involved in DNA repair $[34,35]$. These pathways induced a cascade of protein kinases such as Chk1 and Chk2 (checkpoint kinases), which activate protein p53 inducing $\gamma$-histone $\mathrm{H} 2 \mathrm{AX}$ phosphorylation. Neither p53 nor ChK2 proteins appeared activated in Resox cells (Figures 2(a) and 2(b)), whereas a strong activation was observed in control MCF-7 cells incubated with Asc/Men (Figure 2(a)). Moreover, among the mRNA levels of the different kinases involved in the signaling cascade, only a slight increase of Chk1 mRNA level was observed in Resox cells (Figure 2(c)).

The protein $\mathrm{c}$-abl (Abelson murine leukemia viral oncogene homolog 1) is also induced during the activation of DNA damage pathway [36]. Cao et al. demonstrated that $\mathrm{c}$-abl is capable of phosphorylating catalase leading to its subsequent ubiquitination and degradation by the 




Chromosomes 11

(a)

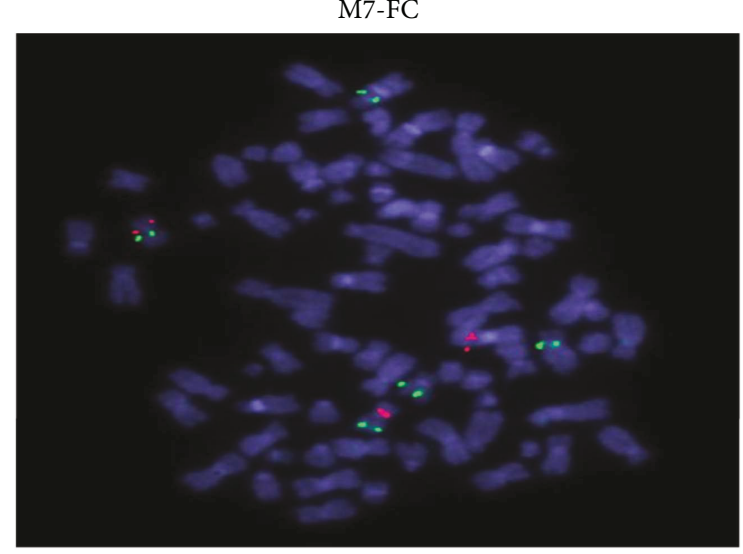

(c)
$250 \mathrm{MK}$

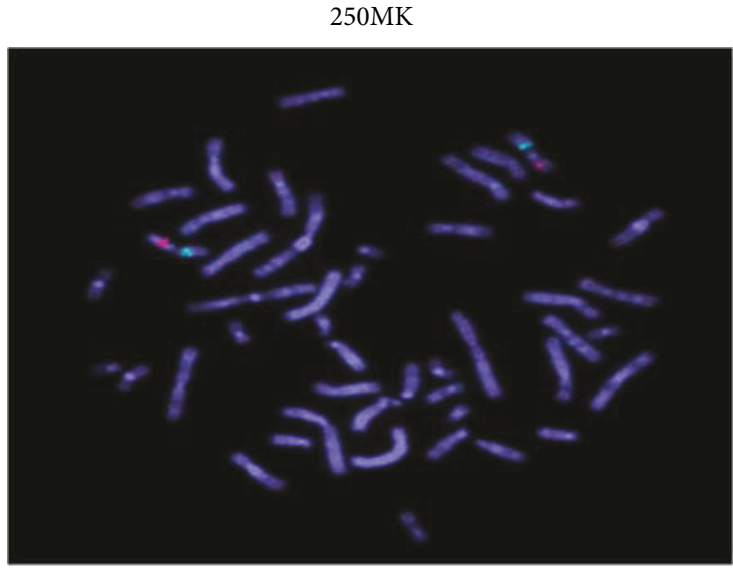

(b)

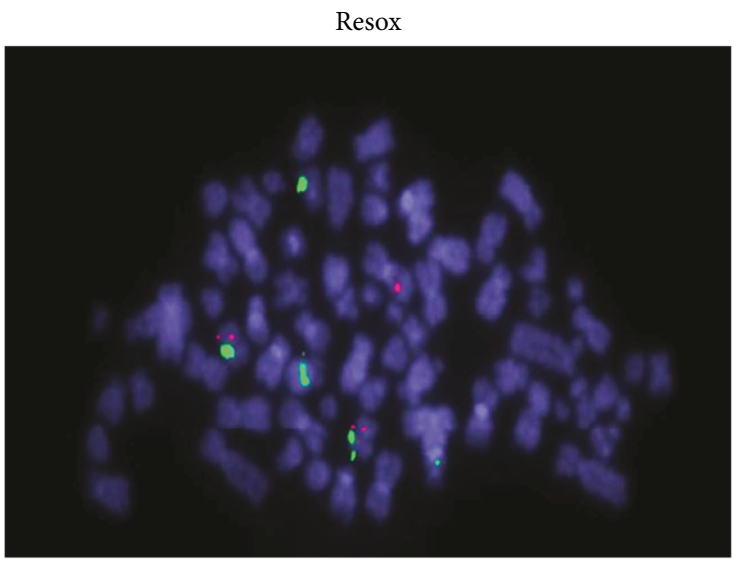

(d)

FIGURE 1: Genomic gain of catalase locus in breast cancer cell lines is not responsible for catalase overexpression in resistant cells. (a) Karyotypes: chromosome 11 of human normal epithelial cells $(250 \mathrm{MK})$ and breast cancer cell lines. (b) Hybridization of catalase (red spots) and control (green spots) FISH probes on metaphases of 250 MK cells. (c) MCF-7 and (d) Resox cells.

proteasome [37, 38]. Interestingly, c-abl mRNA and protein levels were decreased in Resox cells compared to MCF-7 cells (Figures 2(d)-2(f)).

Altogether, these results show that DNA damage pathway is not the cause of catalase overexpression in Resox cells, but posttranslational modifications mediated by c-abl might occur on catalase protein.

\subsection{Are Catalase Covalent Modifications Occurring in Breast} Cancer Cells? Various posttranslational modifications such as phosphorylation, ubiquitination, acetylation, glycosylation, and covalent binding with other proteins (i.e., p53, Atm) have been reported to modulate both catalase expression and activity at different levels [37-43]. The half-life of catalase is generally high, reaching more than 3 days [44-46]. When cells are under oxidative stress conditions, c-abl and c-abl-related gene (Arg) tyrosine kinases are able to phosphorylate catalase at Tyr231 and Tyr386 [37, 38]. The phosphorylated enzyme is subsequently ubiquitinated and degraded by the proteasome. It appears that a physical interaction exists between these kinases and catalase, as demonstrated by immunoprecipitation assays performed in cancer cells and KO MEF (mouse embryonic fibroblast) for the kinases. Furthermore, two proteasome inhibitors, namely, MG132 and lactacystin, also restored catalase expression in these cells [37, 38].

Catalase posttranslational modifications were analysed in our breast cancer cells model. The MG132 proteasome inhibitor did not modify catalase expression in MCF-7 and Resox cells (Figure 3(a)). Finally, catalase phosphorylation did not appear to play a role as a main covalent modification. Indeed, neither ubiquitination nor phosphorylation of catalase was detected after catalase immunoprecipitation (Figure 3(b)), although $\mathrm{c}$-abl protein level was decreased in Resox cell line (Figure 2(e)).

3.4. Are Posttranscriptional Modifications Playing a Role in Catalase Overexpression in Resox Cells? The expression of catalase expression can also be regulated at the RNA level. The catalase gene possesses a $3^{\prime}$ flanking region with T-rich clusters and CA repeats that are susceptible to be regulated by some redox-sensitive proteins, which bind catalase mRNA and enhances translation [47]. Some unidentified proteins could bind to the $5^{\prime}$ UTR (untranslated region) of the catalase mRNA to accelerate the transcriptional rate, as has been observed in cancer PC12 cells exposed to $\mathrm{H}_{2} \mathrm{O}_{2}$ [48] 


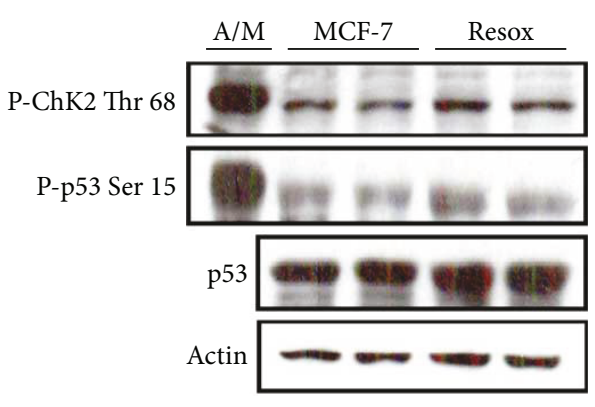

(a)



(c)



(e)

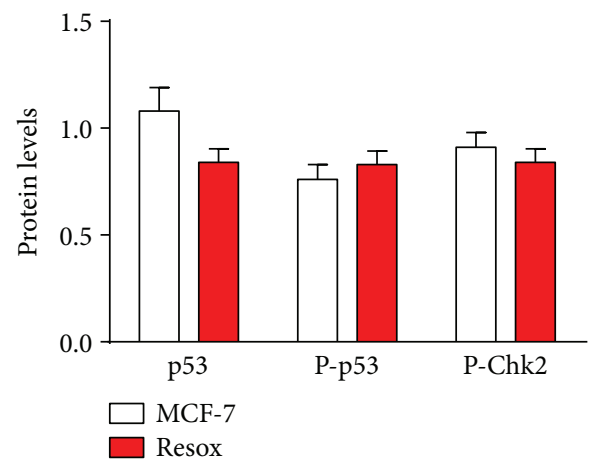

(b)



(d)

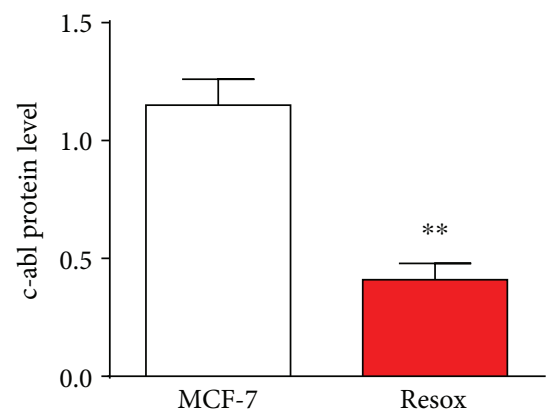

(f)

FIgURE 2: DNA damage pathway did not enhance catalase expression in breast cancer cell lines. (a and b) Immunoblotting and protein quantification of p53, P-p53, and P-Chk2 in breast cancer cells. Ascorbate $1 \mathrm{mM} /$ menadione $10 \mu \mathrm{M}$ (A/M) for $2 \mathrm{~h}$ is used as a positive control to induce DNA damage. (c) mRNA levels of the different kinases activated during the DNA damage pathway. (d) c-abl mRNA level in both MCF-7 and Resox cells. (e and f) Immunoblotting and protein quantification of c-abl in breast cancer cells. Data are mean \pm s.e.m. Groups were compared using unpaired $t$-test. ${ }^{*} p$ value $<0.05 ;{ }^{* *} p$ value $<0.01 ;{ }^{* * *} p$ value $<0.001$.

The microRNA miR-451 can also modulate and enhance catalase expression by suppressing the protein $14-3-3 \xi$, an inhibitor of the FoxO3a (forkhead box O3a) pathway, thereby protecting cells against oxidant drugs [49], but this transcription factor appears to not play a critical role in our models [14]. Moreover, microRNA miR-30b can bind directly to the 3'UTR region of the catalase mRNA, on a conserved site across several species. Mimics of miR-30b can drastically decrease the catalase protein level in human retinal pigment epithelial cell ARPE-19 [50].

In a MCF-7 cell line rendered resistant to $\mathrm{H}_{2} \mathrm{O}_{2}$ and as a result overexpressed catalase, a treatment with actinomycin $\mathrm{D}$ (an inhibitor of the transcription) induces a delay in the degradation of catalase mRNA [51]. As previously shown,
Resox cells have more mRNA than MCF-7 suggesting that mRNA stability in the former cells might be higher than in MCF-7 cells [10]. However, the levels of catalase mRNA did not decrease after 6 hours of actinomycin D incubation in both cells (Figure 4(a)).

\subsection{DNA Methyltransferase Inhibitor Increases Catalase} Protein Level in MCF-7 Cells. Since the transcription of a gene can be regulated by chromatin remodelling due to histone acetylation or DNA methylation, the importance of these mechanisms for the expression of catalase in cancer cells has been raised. In this context, epigenetic changes were proposed to regulate catalase expression in acute myelogenous leukaemia resistant to doxorubicin (AML-2/ 


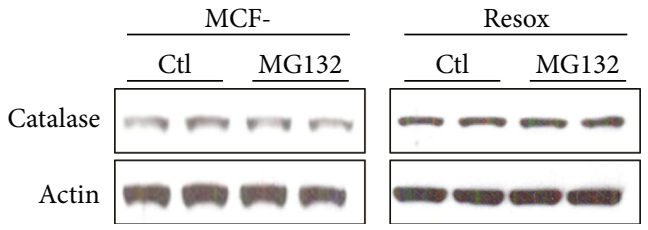

(a)


(b)

Figure 3: Catalase is neither phosphorylated nor ubiquitinated in breast cancer cells. (a) Catalase protein levels were measured after $5 \mathrm{~h}$ incubation with proteasome inhibitor MG132 in both MCF-7 and Resox cells. (b) Immunoprecipitation (IP) with anticatalase antibody and immunoblotting (IB) with anti-Flag, antiphosphocatalase, and catalase antibodies. Prior IP, cells were transfected with a plasmid pcDNA3 $(1 \mu \mathrm{g})$ coding an ubiquitin-Flag for $72 \mathrm{~h}$.

DX100 cells), which exhibit less catalase activity compared to their parental cell lines [52]. Indeed, both Trichostatin A (TSA), an inhibitor of histone deacetylases (HDAC), and 5aza- $2^{\prime}$-deoxycytidine, an inhibitor of DNA methylation, increase the protein levels of catalase in the AML-2/DX100 cells. These data were then confirmed by chromatin immunoprecipitation and sodium bisulfite sequencing assays. The results suggested a hypoacetylation of histones $\mathrm{H} 4$ but not H3. DNA hypermethylation on the catalase promoter in AML-2/DX100 cells was also observed [52]. We have also described the acetylation of histones (at least histone H4), leading to an opening repression of chromatin structures near $-1518 /-1201$ promoter region in MCF-7 cells [10], as shown by ChIP (chromatin precipitation) assays.

DNA methylation is also involved in the regulation of catalase. Indeed, specific CpG islands in the human promoters of catalase and Oct-1 (octamer-binding transcription factor 1: an inducer of catalase gene transcription) genes were methylated in human hepatocellular carcinoma cell line after $\mathrm{H}_{2} \mathrm{O}_{2}$ treatment. This is in good correlation with a decreasing catalase expression in this model $[53,54]$. In this particular type of cancer, the catalase promoter is hypermethylated in the tumor itself but not in the neighbouring tissues [55]. On the contrary, DNA hypomethylation of the catalase gene is frequently observed in colon tumors whereas few modifications of DNA methylation are observed in breast adenocarcinoma compared to normal breast tissues. In the studies where a change in the DNA methylation pattern was observed, DNA hypomethylation and hypermethylation occurred only around the exon 2 of the catalase gene $[55,56]$.

We have thus explored the possibility that DNA methylation may regulate catalase expression in our cellular models.
The DNA methyltransferase (DNMT) inhibitor, 5-aza-2' -deoxycytidine, tends to increase catalase protein level in MCF-7 and not significantly in Resox cells (Figures 4(b) and 4(c)). Moreover, MCF-7 cells became more resistant to prooxidant drugs (Asc/Men) after preincubation with the DNMT inhibitor (Figures 4(d) and 4(e)). Once again, our results demonstrate a potential role of chromatin remodelling in the regulation of catalase expression during cancer cell resistance acquisition to a chronic prooxidant treatment. Consistent with our previous study, methyl CpG-binding proteins (i.e., MECP2) and DNMT (i.e., DNMT1) were identified by AP-MS (affinity purification followed by mass spectrometry) analyses and interact with $-1518 /-1200$ promoter region of catalase gene in MCF-7 cells [10]. Altogether, it suggests that DNA methylation and posttranslational modifications of histones are events associated to repress the transcription of catalase gene. In a panel of 12 cancer cell lines treated with TSA, we confirmed that chromatin remodelling is not a general regulatory mechanism in cancer cells but another breast cancer cell line, an estrogen receptor-negative MDA-MB-231 cell line, also showed increased catalase protein level when incubated with HDAC or RAR $\alpha$ (retinoic acid receptor alpha) inhibitors [10]. Moreover, RAR $\alpha$ overexpression decreased drastically the expression of catalase and histone acetylation was not detected on the catalase promoter by ChIP assay in MDA-MB-231 cells [data not shown], suggesting a similar mechanism regulating catalase expression in these breast cancer cells. In this context, we have recently reported that targeting the redox status of cancer cells by modulating catalase expression is emerging as a novel approach to potentiate chemotherapy [57]. Modifying epigenetic changes such as histone acetylation or DNA methylation in breast cancer cells 


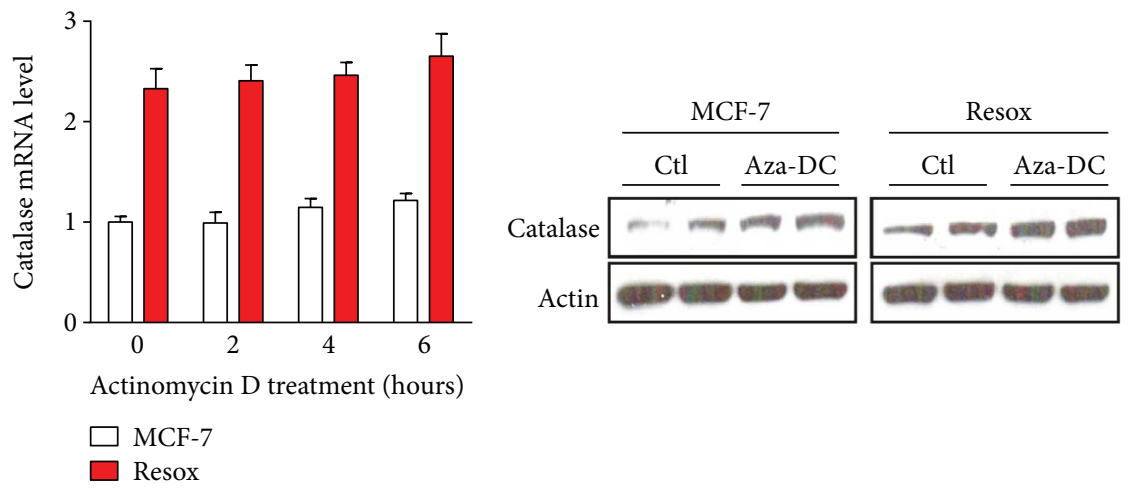

(a)



(c)

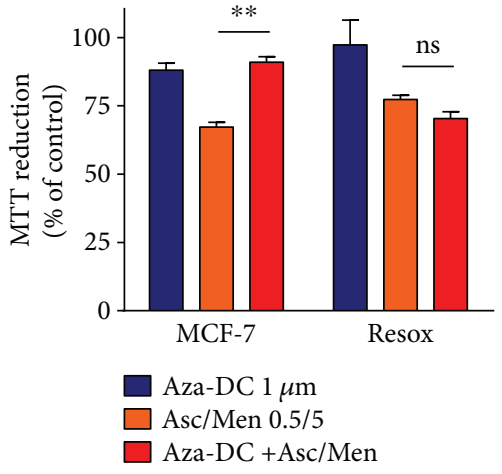

(d)

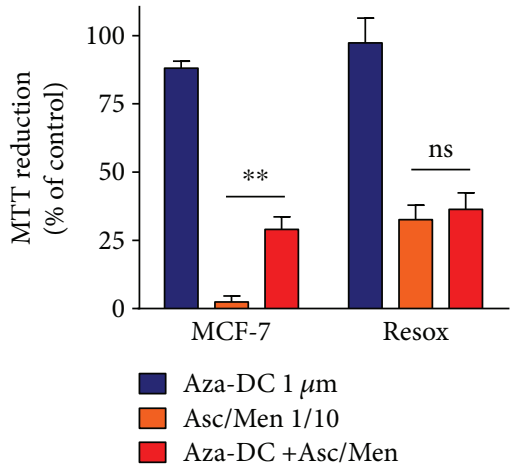

(e)

FIGURE 4: Evaluation of mRNA stability in MCF-7 and Resox cells. DNA methyltransferase inhibitor 5-aza- ${ }^{\prime}$-deoxycytidine tends to increase the levels of catalase protein level in MCF-7 cells. (a) Catalase mRNA levels were measured in MCF-7 and Resox cells after 2, 4, and $6 \mathrm{~h}$ of actinomycin D treatment $(10 \mu \mathrm{g} / \mathrm{ml})$. (b and c) Immunoblotting and protein quantification of catalase, after $72 \mathrm{~h}$ incubation with $1 \mu \mathrm{M}$ of 5 -aza-2' -deoxycytidine (Aza-DC). ( $\mathrm{d}$ and e) Cells were prior incubated with $1 \mu \mathrm{M}$ of 5 -aza- $2^{\prime}$-deoxycytidine for $72 \mathrm{~h}$, then with various concentrations of ascorbate (Asc, $\mathrm{mM}$ ) and menadione (Men, $\mu \mathrm{M})$. Cell survival was measured by MTT assay. Data are mean \pm s.e.m. Groups were compared using unpaired $t$-test. ${ }^{*} p$ value $<0.05 ;{ }^{* *} p$ value $<0.01$.

will thus dramatically alter the expression of various genes including catalase, thus sensitizing cells to prooxidant chemotherapies [3, 10, 57].

\section{Final Concluding Remarks}

Regulatory mechanisms involved in catalase expression occur at different levels from genetic to posttranscriptional modifications including epigenetic and transcriptional processes [3]. Loss of heterozygosity or gene amplification may contribute to an altered expression of catalase but data obtained in this study indicate a minor role as compared to other regulatory mechanisms such as catalase gene transcription as we have recently reported [10, 14]. Meanwhile, although ROS induce DNA damage, the activation of the DNA repair system did not lead to a conclusive role of these pathways on regulation of catalase expression either in MCF-7 or Resox cells. Neither posttranscriptional nor posttranslational modifications are likely involved in the different catalase protein levels in both cell lines. Instead, we have already shown that histones $\mathrm{H} 4$ were acetylated around the promoter region $-1518 /+16$ in Resox cells, explaining the catalase overexpression in these cells. In this study, we have demonstrated that DNA hypo/hypermethylation also plays a pivotal role in this regulation and resistance to prooxidant drugs.

Since catalase expression is sensitive to redox modulation, a therapeutic strategy may be developed in the context of cancer, taking in mind the level of catalase expression. For instance, if catalase is downregulated and the clinical option is to get increased amounts of catalase, an interesting approach would be the use of epigenetic agents (DNMT or HDAC inhibitors) in order to promote a change in chromatin remodelling. Another possibility would be the use of antagonists of $\operatorname{RAR} \alpha$, leading to a pharmacological inhibition of this nuclear receptor and consequently to a loss of catalase repression. Indeed, we recently showed that both compounds, TSA and Ro 41-5255 (HDAC and RAR $\alpha$ inhibitor, resp.), enhance catalase expression not only in MCF-7 cells but also, as previously mentioned, in other mammary cell lines such as the highly aggressive and metastatic MDAMB-231 cells [10]. Conversely, in case of catalase overexpression, a therapeutic option would be the use of siRNA against catalase coupled to nanoparticles or, as we have recently shown, the use of arsenic trioxide (Trisenox) which decreases catalase expression likely by activating the Akt/PKB (protein kinase B) signalling pathway and/or inducing the expression of RAR $\alpha$ [57, unpublished results]. It should be noted that 
the hypothesis suggesting that chromatin remodelling as the main event controlling catalase expression requires both activating and inhibitory factors. Indeed, we have recently shown that the transcription factors JunB and $\operatorname{RAR} \alpha$ are involved in the positive and negative expression of catalase by recruiting coactivators and corepressors leading to chromatin remodelling [10].

Taking together, these findings and previous results obtained in our laboratory $[10,12,14,57]$ suggest that chromatin remodelling is a major regulatory process controlling catalase expression in breast cancer cells during resistance acquisition against an oxidative stress.

\section{Abbreviations}

Akt/PKB: Protein kinase B

AP-MS: Affinity purification followed by mass spectrometry

Arg: $\quad$ c-abl-related gene

ATM: Ataxia telangiectasia mutated

ATR: Ataxia telangiectasia and Rad3 related

Asc/Men: Ascorbate/menadione

c-abl: Abelson murine leukemia viral oncogene homolog 1

ChIP: Chromatin precipitation

Chk: Checkpoint kinase

DNA-PK: DNA-activated protein kinase

DNMT: DNA methyltransferase

FISH: Fluorescence in situ hybridization

FoxO3: Forkhead box O3

HDAC: Histone deacetylase

MEF: $\quad$ Mouse embryonic fibroblast

Oct-1: Octamer-binding transcription factor 1

RAR $\alpha$ : Retinoic acid receptor alpha

ROS: $\quad$ Reactive oxygen species

TSA: Trichostatin A

UTR: Untranslated region

WAGR: Wilms' tumor

Aniridia: Gonadoblastoma and mental retardation (syndrome).

\section{Disclosure}

Christophe Glorieux current address is Sun Yat-Sen University Cancer Center, State Key Laboratory of Oncology in South China, Collaborative Innovation Center of Cancer Medicine, 510275 Guangzhou, China. Nicolas Dejeans current address is Université Bordeaux-Segalen, Inserm U1053, 33000 Bordeaux, France.

\section{Conflicts of Interest}

The authors declare that there are no conflicts of interest.

\section{Acknowledgments}

This project was funded by FNRS-Télévie Grant (Grant no. 7.4575.12F). The authors thank Dr. Anabelle Decottignies (UCL, Brussels, Belgium) for her kind gift of phospho- p53 and Chk2 antibodies. The authors are also grateful to Dr. Martha Stampfer and Dr. James Garbe (Lawrence Berkeley National Laboratory, Berkeley, CA, USA) for the 250MK cells and to Dr. Jean-Baptiste Demoulin (UCL, Brussels, Belgium) for supplying the authors with the plasmid pcDNA3 coding an ubiquitin-Flag.

\section{Supplementary Materials}

Table S1: Oligonucleotides (qRT-PCR). (Supplementary Materials)

\section{References}

[1] M. Nishikawa, M. Hashida, and Y. Takakura, "Catalase delivery for inhibiting ROS-mediated tissue injury and tumor metastasis," Advanced Drug Delivery Reviews, vol. 61, no. 4, pp. 319-326, 2009.

[2] M. C. Winternitz and C. R. Meloy, "On the occurrence of catalase in human tissues and its variations in diseases," The Journal of Experimental Medicine, vol. 10, no. 6, pp. 759-781, 1908.

[3] C. Glorieux, M. Zamocky, J. M. Sandoval, J. Verrax, and P. B. Calderon, "Regulation of catalase expression in healthy and cancerous cells," Free Radical Biology \& Medicine, vol. 87, pp. 84-97, 2015.

[4] L. Goth, P. Rass, and A. Pay, "Catalase enzyme mutations and their association with diseases," Molecular Diagnosis, vol. 8, no. 3, pp. 141-149, 2004.

[5] D. G. Bostwick, E. E. Alexander, R. Singh et al., "Antioxidant enzyme expression and reactive oxygen species damage in prostatic intraepithelial neoplasia and cancer," Cancer, vol. 89, no. 1, pp. 123-134, 2000.

[6] J. Chung-man Ho, S. Zheng, S. A. Comhair, C. Farver, and S. C. Erzurum, "Differential expression of manganese superoxide dismutase and catalase in lung cancer," Cancer Research, vol. 61, no. 23, pp. 8578-8585, 2001.

[7] C. Lauer, A. Volkl, S. Riedl, H. D. Fahimi, and K. Beier, "Impairment of peroxisomal biogenesis in human colon carcinoma," Carcinogenesis, vol. 20, no. 6, pp. 985-989, 1999.

[8] J. Verrax, R. Pedrosa, R. Beck, N. Dejeans, H. Taper, and P. Calderon, "In situ modulation of oxidative stress: a novel and efficient strategy to kill cancer cells," Current Medicinal Chemistry, vol. 16, no. 15, pp. 1821-1830, 2009.

[9] R. Beck, R. C. Pedrosa, N. Dejeans et al., "Ascorbate/menadione-induced oxidative stress kills cancer cells that express normal or mutated forms of the oncogenic protein Bcr-Abl. An in vitro and in vivo mechanistic study," Investigational New Drugs, vol. 29, no. 5, pp. 891-900, 2011.

[10] C. Glorieux, J. M. Sandoval, A. Fattaccioli et al., "Chromatin remodeling regulates catalase expression during cancer cells adaptation to chronic oxidative stress," Free Radical Biology \& Medicine, vol. 99, pp. 436-450, 2016.

[11] Y. Sun, N. H. Colburn, and L. W. Oberley, "Depression of catalase gene expression after immortalization and transformation of mouse liver cells," Carcinogenesis, vol. 14, no. 8, pp. 1505-1510, 1993.

[12] C. Glorieux, N. Dejeans, B. Sid, R. Beck, P. B. Calderon, and J. Verrax, "Catalase overexpression in mammary cancer cells leads to a less aggressive phenotype and an altered response to chemotherapy," Biochemical Pharmacology, vol. 82, no. 10, pp. 1384-1390, 2011. 
[13] N. Dejeans, C. Glorieux, S. Guenin et al., "Overexpression of GRP94 in breast cancer cells resistant to oxidative stress promotes high levels of cancer cell proliferation and migration: implications for tumor recurrence," Free Radical Biology \& Medicine, vol. 52, no. 6, pp. 993-1002, 2012.

[14] C. Glorieux, J. Auquier, N. Dejeans et al., "Catalase expression in MCF-7 breast cancer cells is mainly controlled by PI3K/ Akt/mTor signaling pathway," Biochemical Pharmacology, vol. 89, no. 2, pp. 217-223, 2014.

[15] J. C. Garbe, S. Bhattacharya, B. Merchant et al., "Molecular distinctions between stasis and telomere attrition senescence barriers shown by long-term culture of normal human mammary epithelial cells," Cancer Research, vol. 69, no. 19, pp. 7557-7568, 2009.

[16] B. Marquez, G. Ameye, C. M. Vallet, P. M. Tulkens, H. A. Poirel, and F. van Bambeke, "Characterization of Abcc4 gene amplification in stepwise-selected mouse J774 macrophages resistant to the topoisomerase II inhibitor ciprofloxacin," PLoS One, vol. 6, no. 12, article e28368, 2011.

[17] F. P. Duhoux, G. Ameye, C. P. Montano-Almendras et al., "PRDM16 (1p36) translocations define a distinct entity of myeloid malignancies with poor prognosis but may also occur in lymphoid malignancies," British Journal of Haematology, vol. 156, no. 1, pp. 76-88, 2012.

[18] S. Medves, F. P. Duhoux, A. Ferrant et al., "KANK1, a candidate tumor suppressor gene, is fused to PDGFRB in an imatinib-responsive myeloid neoplasm with severe thrombocythemia," Leukemia, vol. 24, no. 5, pp. 1052-1055, 2010.

[19] C. Glorieux, J. M. Sandoval, N. Dejeans et al., "Overexpression of $\mathrm{NAD}(\mathrm{P}) \mathrm{H}$ :quinone oxidoreductase 1 (NQO1) and genomic gain of the NQO1 locus modulates breast cancer cell sensitivity to quinones," Life Sciences, vol. 145, pp. 57-65, 2016.

[20] T. Mosmann, "Rapid colorimetric assay for cellular growth and survival: application to proliferation and cytotoxicity assays," Journal of Immunological Methods, vol. 65, no. 1-2, pp. 55-63, 1983.

[21] P. Wieacker, C. R. Mueller, A. Mayerova, K. H. Grzeschik, and H. H. Ropers, "Assignment of the gene coding for human catalase to the short arm of chromosome 11," Annales de Génétique, vol. 23, no. 2, pp. 73-77, 1980.

[22] F. Hoffschir, M. Vuillaume, L. Sabatier et al., "Decrease in catalase activity and loss of the $11 \mathrm{p}$ chromosome arm in the course of SV40 transformation of human fibroblasts," Carcinogenesis, vol. 14, no. 8, pp. 1569-1572, 1993.

[23] C. Barletta, M. A. Castello, E. Ferrante et al., "11p13 deletion and reduced $\mathrm{RBC}$ catalase in a patient with aniridia, glaucoma and bilateral Wilms' tumor," Tumori, vol. 71, no. 2, pp. 119121, 1985.

[24] J. L. Dufier, L. H. Phug, P. Schmelck et al., "Intercalary deletion of the short arm of chromosome 11: aniridia, glaucoma, staturoponderal and mental retardation, sexual ambiguity, gonadoblastoma and catalase deficiency," Bulletin des Sociétés d'Ophtalmologie de France, vol. 81, no. 10, pp. 747-749, 1981.

[25] M. J. Gregoire, C. Pernot, F. Himont, M. Pierson, and S. Gilgenkrantz, "Chromosome 11 and cancer," Journal de Génétique Humaine, vol. 31, no. 1, pp. 31-36, 1983.

[26] E. E. Michalopoulos, P. J. Bevilacqua, N. Stokoe, V. E. Powers, H. F. Willard, and W. H. Lewis, "Molecular analysis of gene deletion in aniridia-Wilms tumor association," Human Genetics, vol. 70, no. 2, pp. 157-162, 1985.
[27] L. Sabatier, F. Hoffschir, W. A. al Achkar, C. Turleau, J. de Grouchy, and B. Dutrillaux, "The decrease of catalase or esterase D activity in patients with microdeletions of $11 p$ or $13 q$ does not increase their radiosensitivity," Annales de Génétique, vol. 32, no. 3, pp. 144-148, 1989.

[28] E. N. Sotnikova, L. A. Durnov, R. V. Zhordania, R. F. Gar'kavtseva, and A. F. Bukhny, "Changes in the hemoglobin fractions of nephroblastoma patients," Genetika, vol. 20, no. 2, pp. 357-361, 1984.

[29] V. van Heyningen, P. A. Boyd, A. Seawright et al., "Molecular analysis of chromosome 11 deletions in aniridia-Wilms tumor syndrome," Proceedings of the National Academy of Sciences of the United States of America, vol. 82, no. 24, pp. 8592-8596, 1985.

[30] K. M. Fong, P. V. Zimmerman, and P. J. Smith, "Correlation of loss of heterozygosity at $11 \mathrm{p}$ with tumour progression and survival in non-small cell lung cancer," Genes, Chromosomes \& Cancer, vol. 10, no. 3, pp. 183-189, 1994.

[31] C. U. Ludwig, G. Raefle, P. Dalquen, P. Stulz, R. Stahel, and J. P. Obrecht, "Allelic loss on the short arm of chromosome 11 in non-small-cell lung cancer," International Journal of Cancer, vol. 49, no. 5, pp. 661-665, 1991.

[32] R. Shipman, P. Schraml, M. Colombi, and C. U. Ludwig, "Allelic deletion at chromosome 11p13 defines a tumour suppressor region between the catalase gene and D11S935 in human non-small cell lung carcinoma," International Journal of Oncology, vol. 12, no. 1, pp. 107-111, 1998.

[33] M. Yamada, K. Hashinaka, J. Inazawa, and T. Abe, "Expression of catalase and myeloperoxidase genes in hydrogen peroxideresistant HL-60 cells," DNA and Cell Biology, vol. 10, no. 10, pp. 735-742, 1991.

[34] J. Rouse and S. P. Jackson, "Interfaces between the detection, signaling, and repair of DNA damage," Science, vol. 297, no. 5581, pp. 547-551, 2002.

[35] B. B. Zhou and S. J. Elledge, "The DNA damage response: putting checkpoints in perspective," Nature, vol. 408, no. 6811, pp. 433-439, 2000.

[36] E. Maiani, M. Diederich, and S. Gonfloni, "DNA damage response: the emerging role of c-Abl as a regulatory switch?," Biochemical Pharmacology, vol. 82, no. 10, pp. 1269-1276, 2011.

[37] C. Cao, Y. Leng, and D. Kufe, "Catalase activity is regulated by c-Abl and Arg in the oxidative stress response," The Journal of Biological Chemistry, vol. 278, no. 32, pp. 29667-29675, 2003.

[38] C. Cao, Y. Leng, X. Liu, Y. Yi, P. Li, and D. Kufe, "Catalase is regulated by ubiquitination and proteosomal degradation. Role of the c-Abl and Arg tyrosine kinases," Biochemistry, vol. 42, no. 35, pp. 10348-10353, 2003.

[39] H. Furuta, A. Hachimori, Y. Ota, and T. Samejima, "Dissociation of bovine liver catalase into subunits on acetylation," The Journal of Biochemistry, vol. 76, no. 3, pp. 481-491, 1974.

[40] M. Y. Kang, H. B. Kim, C. Piao et al., "The critical role of catalase in prooxidant and antioxidant function of p53," Cell Death \& Differentiation, vol. 20, no. 1, pp. 117-129, 2013.

[41] R. Rafikov, S. Kumar, S. Aggarwal et al., "Endothelin-1 stimulates catalase activity through the $\mathrm{PKC} \delta$-mediated phosphorylation of serine 167," Free Radical Biology \& Medicine, vol. 67, pp. 255-264, 2014.

[42] D. Watters, P. Kedar, K. Spring et al., "Localization of a portion of extranuclear ATM to peroxisomes," The Journal of Biological Chemistry, vol. 274, no. 48, pp. 34277-34282, 1999. 
[43] H. Yan and J. J. Harding, "Glycation-induced inactivation and loss of antigenicity of catalase and superoxide dismutase," The Biochemical Journal, vol. 328, no. 2, pp. 599-605, 1997.

[44] A. Geerts, B. De Prest, and F. Roels, "On the topology of the catalase biosynthesis and -degradation in the guinea pig liver. A cytochemical study," Histochemistry, vol. 80, no. 4, pp. 339-345, 1984.

[45] B. Poole, "The kinetics of disappearance of labeled leucine from the free leucine pool of rat liver and its effect on the apparent turnover of catalase and other hepatic proteins," The Journal of Biological Chemistry, vol. 246, no. 21, pp. 6587-6591, 1971.

[46] B. Poole, F. Leighton, and C. De Duve, "The synthesis and turnover of rat liver peroxisomes," The Journal of Cell Biology, vol. 41, no. 2, pp. 536-546, 1969.

[47] B. Ghosh, E. Barbosa, and I. Singh, "Characterization of fibroblast cytoplasmic proteins that bind to the $3^{\prime}$ UTR of human catalase mRNA," Molecular and Cellular Biochemistry, vol. 209, no. 1-2, pp. 9-15, 2000.

[48] D. Sampath and R. Perez-Polo, "Regulation of antioxidant enzyme expression by NGF," Neurochemical Research, vol. 22, no. 4, pp. 351-362, 1997.

[49] D. Yu, C. O. dos Santos, G. Zhao et al., "miR-451 protects

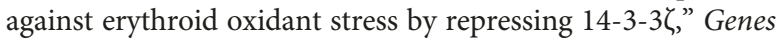
\& Development, vol. 24, no. 15, pp. 1620-1633, 2010.

[50] R. Haque, E. Chun, J. C. Howell, T. Sengupta, D. Chen, and H. Kim, "MicroRNA-30b-mediated regulation of catalase expression in human ARPE-19 cells," PLoS One, vol. 7, no. 8, article e42542, 2012.

[51] S. A. Akman, G. Forrest, F. F. Chu, and J. H. Doroshow, "Resistance to hydrogen peroxide associated with altered catalase mRNA stability in MCF7 breast cancer cells," Biochimica et Biophysica Acta (BBA) - Gene Structure and Expression, vol. 1009, no. 1, pp. 70-74, 1989.

[52] T. B. Lee, Y. S. Moon, and C. H. Choi, "Histone H4 deacetylation down-regulates catalase gene expression in doxorubicinresistant AML subline," Cell Biology and Toxicology, vol. 28, no. 1, pp. 11-18, 2012.

[53] J. Y. Min, S. O. Lim, and G. Jung, "Downregulation of catalase by reactive oxygen species via hypermethylation of $\mathrm{CpG}$ island II on the catalase promoter," FEBS Letters, vol. 584, no. 11, pp. 2427-2432, 2010.

[54] X. Quan, S. O. Lim, and G. Jung, "Reactive oxygen species downregulate catalase expression via methylation of a CpG island in the Oct-1 promoter," FEBS Letters, vol. 585, no. 21, pp. 3436-3441, 2011.

[55] S. Ding, B. D. Gong, J. Yu et al., "Methylation profile of the promoter CpG islands of 14 "drug-resistance" genes in hepatocellular carcinoma," World Journal of Gastroenterology, vol. 10, no. 23, pp. 3433-3440, 2004.

[56] S. Ribieras, X. G. Song-Wang, V. Martin, P. Lointier, L. Frappart, and R. Dante, "Human breast and colon cancers exhibit alterations of DNA methylation patterns at several DNA segments on chromosomes 11p and 17p," Journal of Cellular Biochemistry, vol. 56, no. 1, pp. 86-96, 1994.

[57] C. Glorieux and P. B. Calderon, "Catalase, a remarkable enzyme: targeting the oldest antioxidant enzyme to find a new cancer treatment approach," Biological Chemistry, vol. 398, no. 10, pp. 1095-1108, 2017. 




The Scientific World Journal
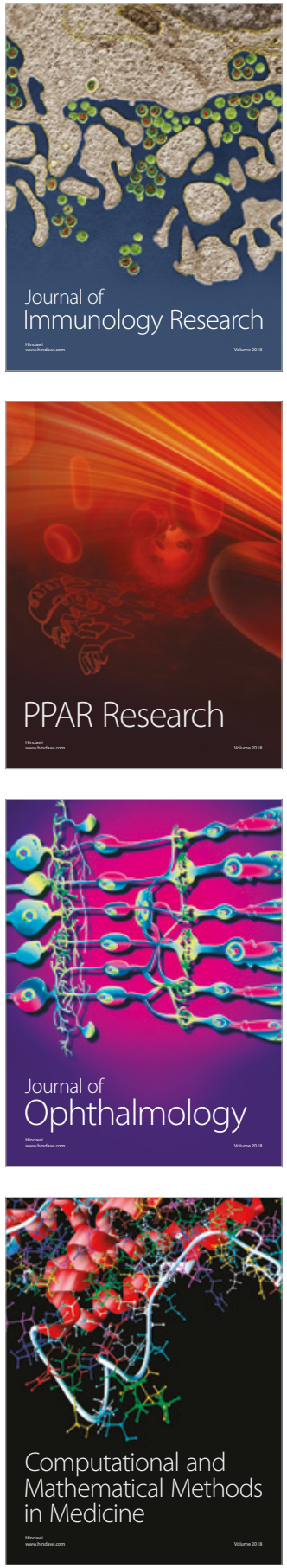

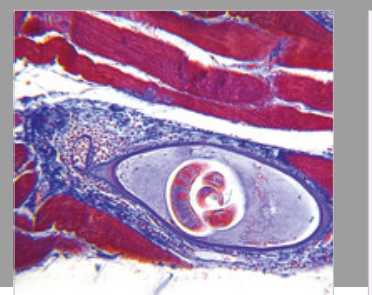

Gastroenterology Research and Practice

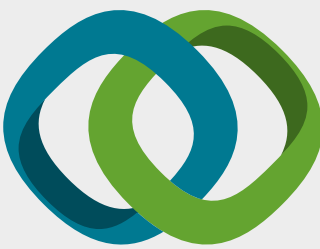

\section{Hindawi}

Submit your manuscripts at

www.hindawi.com
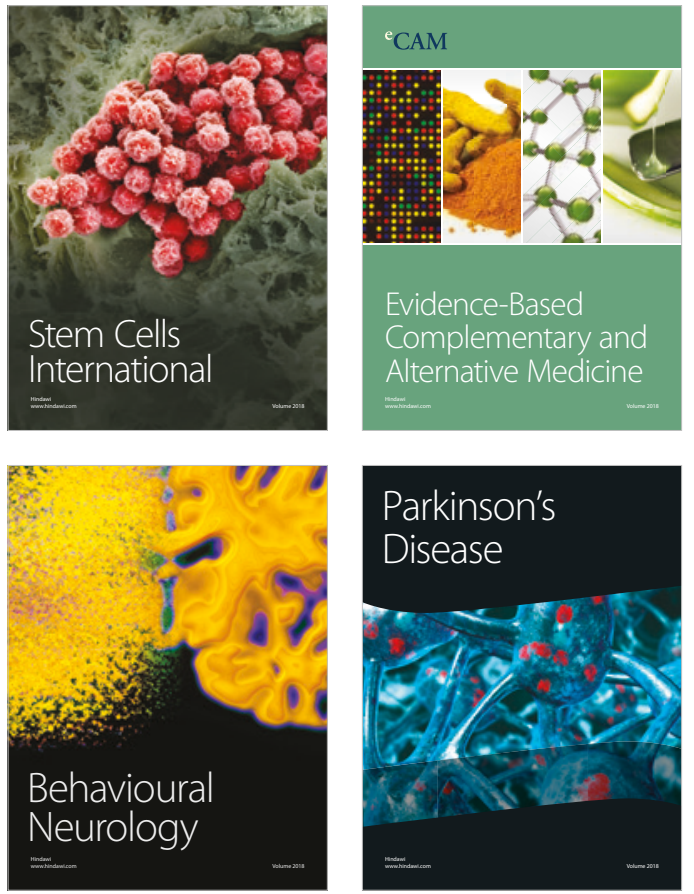

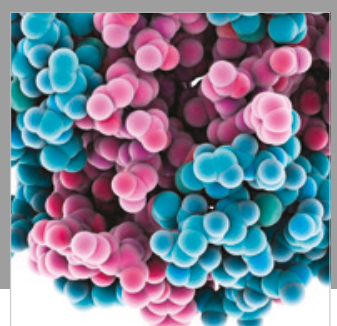

ournal of

Diabetes Research

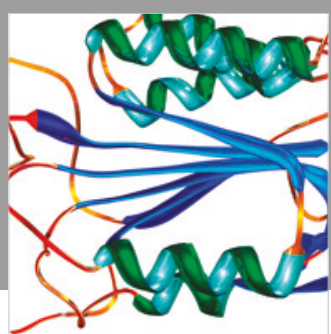

Disease Markers
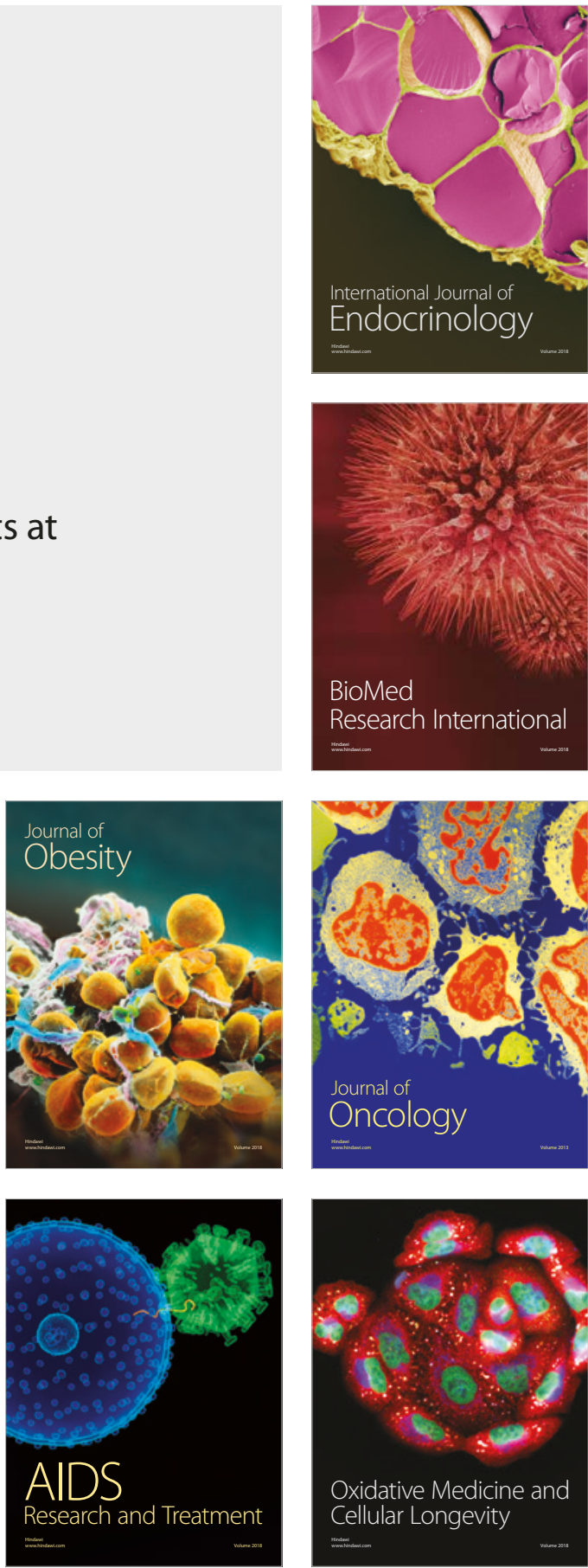